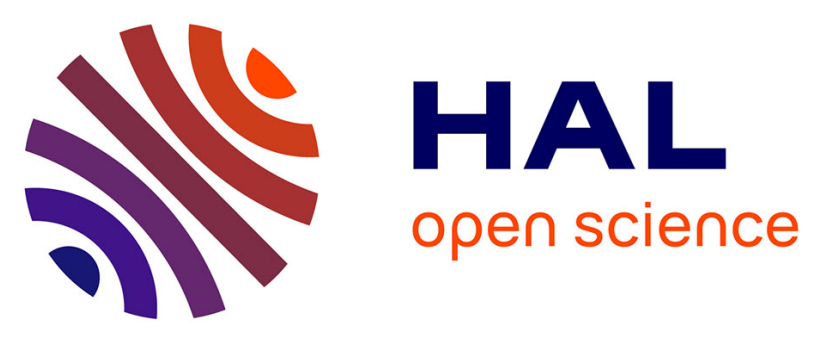

\title{
Determination of total hydrocarbons in contaminated soil with "Thin Layer Sorptive Extraction coupled with Attenuated Total Reflectance -Fourier Transform Infrared
}

Houssein Louati, Sébastien Maria, Jean-François Rocci, Pierre Doumenq

\section{To cite this version:}

Houssein Louati, Sébastien Maria, Jean-François Rocci, Pierre Doumenq. Determination of total hydrocarbons in contaminated soil with "Thin Layer Sorptive Extraction coupled with Attenuated Total Reflectance -Fourier Transform Infrared. Analytical Chemistry, 2020, 92 (23), pp.15344-15351. 10.1021/acs.analchem.0c02493 . hal-03154744

\author{
HAL Id: hal-03154744 \\ https://hal.science/hal-03154744
}

Submitted on 1 Mar 2021

HAL is a multi-disciplinary open access archive for the deposit and dissemination of scientific research documents, whether they are published or not. The documents may come from teaching and research institutions in France or abroad, or from public or private research centers.
L'archive ouverte pluridisciplinaire HAL, est destinée au dépôt et à la diffusion de documents scientifiques de niveau recherche, publiés ou non, émanant des établissements d'enseignement et de recherche français ou étrangers, des laboratoires publics ou privés. 


\title{
Determination of total hydrocarbons in contaminated soil with "Thin Layer Sorptive Extraction coupled with
} Attenuated Total Reflectance - Fourier Transform Infrared Spectroscopy"' Houssein LOUATI ${ }^{1,2,3}$, Sébastien MARIA*22, Jean-François ROCCI ${ }^{3}$, Pierre DOUMENQ ${ }^{1}$

1- Aix-Marseille Univ, CNRS, LCE, UMR CNRS 7376, Europole de l'Arbois Bât Villemein BP 80-13545 Aixen-Provence, France

2- Aix-Marseille Univ, CNRS, Institut de Chimie Radicalaire UMR 7273-team CROPS, Avenue Escadrille Normandie Niemen,13013 Marseille, France

3- Société Environnement Investigations, 13990, Fontvieille, France

*Corresponding author

E-mail : sebastien.maria@univ-amu.fr Phone : +33(0)491288192

\begin{abstract}
Soil analyzing using infrared spectroscopy has been proposed as an alternative to conventional soil analysis to detect soil contamination. This study therefore aims to develop an innovative, in situ, rapid, precise, and inexpensive method that is easy to implement in order to assess soil contamination with hydrocarbons. This work describes, the development and validation of a new extraction method by Thin Layer Sorptive Extraction and Attenuated Total Reflectance-Fourier Transform InfraRed spectroscopy (TLSE-ATR-FTIR). First, this method allows the preconcentration of thermodesorbed pollutants on a polymer thin film and then, their quantification by ATR-FTIR using standard addition method. A five factors fractional factorial design (FFD) was used to identify the most significant factors impacting the analysis. These factors include soil texture, total organic carbon (TOC), humidity, and concentrations of contaminants. The results showed that TOC, nature (clay, sandy and loamy) of the soil and the concentration of pollutants can affect the infrared absorbance. The analytical method has been validated by verifying the different performance criteria such as linearity, accuracy, precision, and quantitation limit. The comparison of the results obtained by TLSE-ATR-FTIR to the results of conventional analyzes carried out by accredited laboratories confirms that the use of the proposed method can become an effective alternative to the current methods for the determination of the total hydrocarbons in soils.
\end{abstract}

According to the European Environment Agency, total hydrocarbons (THC) (alkanes, alkenes, and cycloalkanes) was one of the main pollutants in European contaminated sites forming $33.7 \%$ of total soil contaminants ${ }^{1}$. Soil pollution by hydrocarbons is frequent and originates from tank leakages, service stations, etc. In fact, contamination by THC is one of the most frequently encountered in the field of polluted sites and soils, especially since these products are toxic to humans and to the environment ${ }^{2}$. THC is categorized in four broad fractions (a) aliphatic saturates e.g. alkanes, branched and naphthenic compounds) (b) aromatics (polycondensed parent- and alkylated) hydrocarbons), (c) resins and (d) asphaltenes ${ }^{3,4}$ Contamination severity is typically characterized by the concentration of hydrocarbons. In order to remediate and monitor cleaning processes and also to evaluate the final quality of the soil, it is becoming increasingly urgent to assess contamination in some concerned sites ${ }^{5}$, especially if a "reuse" is planned for other purposes.

The quantification of THC can be performed by different analytical methods in specialized laboratories using documented and certified methods and instruments. These analyses are usually based on gravimetry such as USEPA methods $9071 \mathrm{~B}$, fluorimetry ${ }^{6}$ and chromatography with flame ionization detection (GC-FID) ${ }^{7}$ or mass spectrometry detection (GC-MS) $)^{8}$ These analyses are typically preceded by a solvent extraction using an organic solvent, an extraction device (soxhlet, microwave assisted extraction (MAE), accelerated solvent extraction (ASE), sonication, etc.) and usually have a purification step afterwards. However, these laboratory methods cannot, for various reasons, be used in the field for direct monitoring. In addition, these methods can take from a couple of hours to several days, thus they are not sufficiently fast and do not provide a high frequency of analyses that is for example necessary in the soil cleaning process.

In this frame, alternatives to such laboratory analyses must be considered. Among them, the spectral approaches seem to be suitable $\mathrm{e}^{8-10}$.

Horta et al. 2015 has shown that there are a few researchers who have addressed the problem of application of spectroscopic determination of THC in soil ${ }^{11}$. Wright et al. (1995) reported that using field measurement methods instead of laboratory analyses are possible and allow to analyze more soil samples, faster and at a lower cost ${ }^{12,13}$.

Besides, from the 2000s, some teams showed the feasibility of such soil analyses, notably using the Fourier Transform InfraRed (FTIR) spectroscopy ${ }^{13-15}$ but mainly in near IR because the mid-infrared (MIR) is cramped by humidity of 
soils $^{16-19}$. In addition, infrared spectra of soils can be affected by various interactions with the mineral and/or organic matrix which can lead to a significant increase or decrease in the response of an analyte in a sample compared with the pure compound or a pure standard solution ${ }^{20}$

More recently, Pejcic et al. 2015 worked on the analysis of contaminants in water using active samples for trace analysis of hydrocarbons and chlorinated contaminant ${ }^{21,22}$. This sampling is based on the accumulation of compounds present in the water sample onto a polymeric sampler deposited on a $\mathrm{ZnSe}$ window inside a circulation cell followed by the quantification in the mid-infrared with ATR-FTIR.

The extraction of THC in water and air using a solid phase microextraction with polydimethylsiloxane (PDMS) phases were described in literature ${ }^{23-27}$. This led us to develop the concept of using a disposable thin polymeric film of PDMS coupled with ATR-FTIR for the analysis of total hydrocarbons in soil. Firstly, this method allows the preconcentration of thermodesorbed pollutants on a polymer thin film and secondly, their direct quantification by ATR-FTIR. This technique allows to quantify simultaneously many organic compounds without the need of the laboratory steps and complex data analysis and/or corrections. Then it will support the implementation of green chemistry principles as, in contrast to the former chromatographic or IR-spectroscopy based methods, it avoids the use of halogenated solvents. We decided to name this technique as Thin Layer Sorptive Extraction (TLSE)-ATR-FTIR.

PDMS is a non-toxic, highly hydrophobic, translucent polymer that does not bioaccumulate in living organisms ${ }^{28}$. PDMS is an elastomeric material used in various fields as aeronautics, electronics (insulation), biomedical and chemical analysis ${ }^{29}$. The first notable application of PDMS in analytical chemistry was its use as a stationary phase in gas liquid chromatography (GLC) ${ }^{29}$.

This study therefore aims to develop an innovative, in situ, rapid, precise and inexpensive method that is easy to implement in order to assess soil contamination with hydrocarbons with TLSE-ATR-FTIR. Thus this work will focus on: a) the applicability of ATR-FTIR technique to the analysis of soils contaminated with total hydrocarbons, b) the influence of Soil physical and chemicals properties such as nature (clay, sandy and loamy), humidity, organic content on THC extraction performance and quantification and c) the evaluation of the performance of TLSE-ATR-FTIR for the analysis of soils with different levels of contamination. This work is sought to provide a response to these questions and to supply more complete information on the potentials and limitations of IR techniques applied to THC determination.

\section{MATERIAL AND METHODS}

\section{Chemicals and instruments}

Hexane, acetone, and methanol (Fisher Scientific), dichloromethane and pentane were purchased from VWR Chemicals. All the solvents used were HPLC grade.

Mineral oil and gas oil standards were purchased from Aldrich. These standards are used for hydrocarbons determination according to ISO X31-410 (1994) ${ }^{30}$ to provide a mixture of hydrocarbons in the range $\mathrm{C}_{10}$ and $\mathrm{C}_{40}{ }^{31}$. Stock standard solutions of $1 / 1(\mathrm{w} / \mathrm{w})$ mineral oil/standard gas oil were used for calibration.

The Silicone Elastomer SYLGARD 184 kit (Dow Corning ${ }^{\mathrm{TM}}$ ) was obtained from NEYCO-France. Sylgard 184 is a two-component system kit with a PDMS polymeric base and a curing agent (cross-linker). Stainless steel (AISI 304) magnetizable disks ( $1 \mathrm{~cm}$ diameter and $2 \mathrm{~mm}$ height) were provided by VEGATEC.

The uncontaminated soils (blank samples) used to validate the method were provided from CEREGE. The THC analyses were performed on a transportable spectrometer infrared system (Spectrum 2 from Perkin- Elmer). Spin coater SPIN150 (SPS) was used for preparing thin PDMS films of different thickness values. A Mitutoyo micrometer was used to measure and control the thickness of PDMS layers. For the thinner films $(<5 \mu \mathrm{m})$ we used ellipsometry (Woollam M2000 V).

\section{TLSE Polymeric sampler Manufacturing}

Spin-coating is a flexible approach as well as the most widely used method for preparing thin PDMS films of different thickness values ${ }^{32}$. The spin coating process begins with cleaning the substrate (stainless steel disk) to remove contaminants, then drying using nitrogen. The most common method for preparing a silicone sample is using a PDMS pre-polymer and a cross-linker in a 10:1 ratio. The mixture of pre-polymer and cross-linker is stirred, degassed (20 minutes) in a desiccator under vacuum and finally spin-coated on the disk. During spin-coating, a small volume of about $0.2 \mathrm{ml}$ of PDMS (with cross-linker) is poured near the center of the disk. The spin-coating rotation speed (rpm) and duration (s) were optimized in order to obtain the desired final thickness. For example, in our case, spin-coating at $4000 \mathrm{rpm}$ for 60 seconds yields to a repeatable PDMS film of about $10 \mu \mathrm{m}$ thick. The sample is then baked in an oven at $150{ }^{\circ} \mathrm{C}$ for 20 minutes to achieve reticulation and develop good mechanical and adhesion properties. The final thickness of the film is measured with a precision micrometer.

\section{Preparation of spiked soil samples}

Four uncontaminated soils (blank samples), with documented and different chemical and physical properties were kindly provided by Prof. Keller (CEREGE-France). These samples were pre-dried in a forced-air oven at $50^{\circ} \mathrm{C}$ for 24 hours, ground and sieved to a size smaller than $2 \mathrm{~mm}$.

A spiking solution was prepared in dichloromethane by mixing reference gasoil and mineral oil (50\%:50\%/w:w). 
$5 \mathrm{~g}$ of uncontaminated soil samples were fortified at different THC levels (100, 200, 300, 500, 700 et $\left.1000 \mathrm{mg} \cdot \mathrm{kg}^{-1}\right)$. Then, spiked soils were vortexed for 30 seconds. Then, spiked samples were air-dried for $10 \mathrm{~h}$ at room temperature so that the complete evaporation of the solvent occurred. During this step, different measurements in the headspace of the soil container were made to ensure the evaporation of the excess solvent. The soils are then stored in the dark for 21 days, in order to simulate weathering and allow analytes-matrix interactions to occur to an extent close to "real-world" contaminated soils of similar properties ${ }^{15,33}$.

\section{Soils thermodesorption and polymeric film analysis by ATR-FTIR}

The identification and quantification of THC were performed using a field FTIR spectrometer (Perkin Elmer Spectrum 2), equipped with attenuated total reflectance module (with a diamond internal reflection element) and a standard DTGS detector. All IR spectra were the result of 32 interferogram accumulations at the resolution of $4 \mathrm{~cm}^{-1}$, in the 4000 to $450 \mathrm{~cm}^{-1}$ range.

First, the infrared spectrum of a "blank" captor with the adequate thickness was obtained before extraction. This spectrum represents the reference spectrum and is used to subtract the characteristic IR bands of the PDMS film. The spiked soil is disposed into a $50 \mathrm{ml}$ borosilicate vial (PTFE capped), heated in a specific aluminum heating-block soil for 45 minutes at $300{ }^{\circ} \mathrm{C}$ in order to obtain a fast thermodesorption of the contaminants. This optimal condition was determined according to the results of preliminary "step by step" test (unpublished data).

Hydrocarbons are extracted from the gas phase as the sampler is placed thanks to a magnet in the upper head space (Figure 1). After the extraction step, the stainless-steel disk with PDMS layer is directly analyzed by ATR-FTIR in order to obtain a sample spectrum. The interactive subtraction between the sample spectrum (PDMS +THC) and the reference spectrum (only PDMS) provides the spectrum resulting from the organic compound extract on the polymer film. THC concentrations are then determined by the absorbances of the characteristic bands used in the IR scans ranging from $3000 \mathrm{~cm}^{-1}$ to $2700 \mathrm{~cm}^{-1}$.

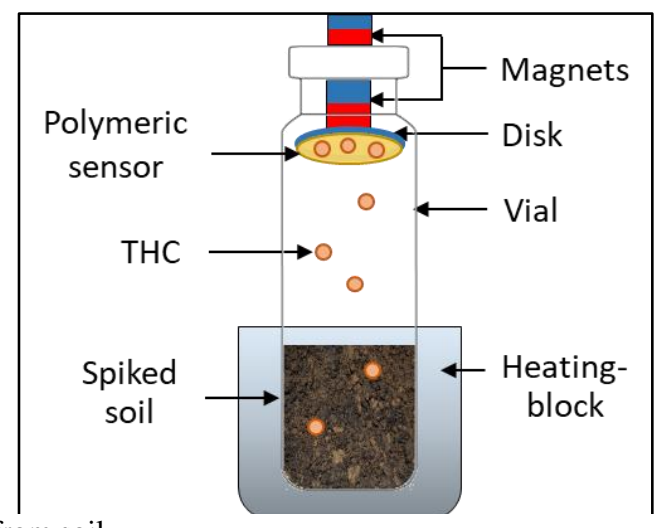

Figure 1 : Thermodesorption of HCT from soil

\section{Determination of influencing factors by experimental design}

The study of the factors influencing TLSE of THC was carried out with a 2-level fractional factorial matrix. Azurad ${ }^{(\mathrm{TM})}$ software was used for the design and analysis of the experiments. The most important experimental factors were selected after a preliminary step by step study.

The fractional factorial matrix was used for screening 5 factors (nature of the soil (sandy and clay), water content, organic carbon content, concentration of pollutants and the effect of desiccant $\left(\mathrm{Na}_{2} \mathrm{SO}_{4}\right)$ addition) with two different levels. The investigated factors and their respective levels are presented in Table 1.

Regarding Total Organic Carbon (TOC) and soil nature (sandy and clay), we have selected a set of well-documented "natural" soils (Fontainebleau sand, Podzol, green clay and conventional soil) with different organic carbon levels and nature as shown Table 2

Table 1: Levels of factors and their assigned codes

\begin{tabular}{|c|c|c|c|}
\hline Factors & Code factors & Level - & Level + \\
\hline Humidity & $\mathrm{X} 1$ & $1 \%$ & $30 \%$ \\
\hline [Pollutants] & $\mathrm{X} 2$ & 400 & 3000 \\
\hline Soil nature & $\mathrm{X} 3$ & Sand & Clay \\
\hline TOC & $\mathrm{X} 4$ & $<0.5 \%$ & $>2 \%$ \\
\hline $\mathrm{Na} 2 \mathrm{SO} 4$ & $\mathrm{X} 5$ & Low & Hight \\
\hline
\end{tabular}


Table 2: Chemical composition and particle size of uncontaminated soils

\begin{tabular}{|c|c|c|c|c|c|}
\hline Soil & 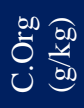 & ⿹ & 홀 & త & 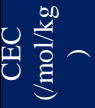 \\
\hline Podzol & 20.4 & 93.9 & 4.1 & 2 & 5.92 \\
\hline Conventional & 30.4 & 18.1 & 34.5 & 47 & 22.6 \\
\hline Fontainebleau.S & 0.12 & 99 & - & - & - \\
\hline Green Clay & 0.5 & - & - & 99 & 34.3 \\
\hline
\end{tabular}

Humidity levels of $1 \%$ and $30 \%$ were also tested by adding water to different samples pre and post-spiking. These conditions were chosen based on unpublished data on natural contaminated soils. Then, $\mathrm{Na}_{2} \mathrm{SO}_{4}$ was used in case the humidity had a significant impact on THC extraction. THC concentration tested were 400 and $3000 \mathrm{mg} . \mathrm{kg}^{-1}$.

\section{TLSE-ATR-FTIR method validation}

Validation of Linearity: Linearity was determined by a series of analyses of standards adsorbed in the film. The response is directly proportional to the concentrations of the analytes. To evaluate linearity in a field of calibration, six levels of concentration were used. The process was repeated three times in the conditions of intermediate precision from spiking solution. The linearity is evaluated by the coefficient of determination $\left(\mathrm{R}^{2}\right)$ and the relative standard deviation RSD (\%). The calibration curves were constructed from the response versus the concentration of the standards.

Validation of accuracy: Accuracy is assessed by analyzing a spiked different sample and comparing the measured value with the spiked concentration. It is evaluated by repetitively spiking the matrix with known levels of analytes standard. For each sample and each series, two repetitions were performed in the conditions of repeatability. The accuracy (\%) was expressed as:

$$
\% \text { accuracy }=\frac{\text { abs (true value }- \text { measured value }) * 100}{\text { true value }}
$$

Accuracy is evaluated thanks to a comparison using an acceptance quality level (AQL) of the reference value by the recovery values obtained after the extraction process.

Validation of precision: Precision is evaluated thanks to the intra-day and inter-day precisions. They are evaluated by the repeated analysis of different film PDMS containing hydrocarbons. Three concentrations corresponding to concentrations located lower, middle, and upper calibration curves were prepared in uncontaminated soil (the same concentration used to study the accuracy).

- The intra-day experiment was obtained by ATR-FTIR analysis by three replicates at three different concentrations for a day.

- The inter-day precision was determined by three analyses of replicates at three different concentrations for different days.

Validation of LOQ: The aim of this part is to check if the assumed limit of quantification is admissible in the considered matrix. This parameter is determined by replicate $(\mathrm{n}=2)$ analysis of spiked soil prepared at presupposed LOQ (300 mg.kg-1) in five uncontaminated soils. LOQ is evaluated thanks to a comparison using an acceptance quality level (AQL), with verifying these two following inequalities:

1. $\mathrm{zLOQ}-2 \times \mathrm{sFI}>\mathrm{LOQ}-(\mathrm{AQL} \% \times \mathrm{LOQ})$

2. $\mathrm{zLOQ}+2 \times \mathrm{sFI}<\mathrm{LOQ}+(\mathrm{AQL} \% \times \mathrm{LOQ})$

With zLOQ average of measured concentration and sFI standard deviation of precision.

\section{RESULTS AND DISCUSSION}

\section{Kinetic study of hydrocarbons accumulation on the polymeric sampler}

The accumulation kinetic of THC in PDMS thin layer (polymeric sampler) was studied at various times ranging from 10 to $90 \mathrm{~min}$ and the results are shown in the Figure 1 SI. An increase in the amount of THC fixed on the PDMS film is observed up to a duration of 40 minutes. Beyond this, the equilibrium was reached. The quantification of hydrocarbons in the study of sorption kinetic of hydrocarbons was established by external calibration. Note that an optimization of the thickness of the polymeric film was carried out (Figure 2 SI). 
The associated model of THC sorption kinetic onto the PDMS follows the pseudo-second order (Figure 1 SI).

The R-squared $\left(\mathrm{R}^{2}\right)$ is equal to 0.994 showing a very good correlation between the modeled and experimental values. A pseudo-second-order kinetic model implies that the sorption process is both a chemical sorption and a physical sorption $^{34}$.

\section{TLSE hydrocarbons identification and quantification}

\section{Identification}

Figure 2 shows that on the MIR spectrum a weak band appeared at $2961 \mathrm{~cm}^{-1}$, this band is easily subtractable from the spectra of THC. Thus, after subtraction, the bands of THC were obtained without interferences.

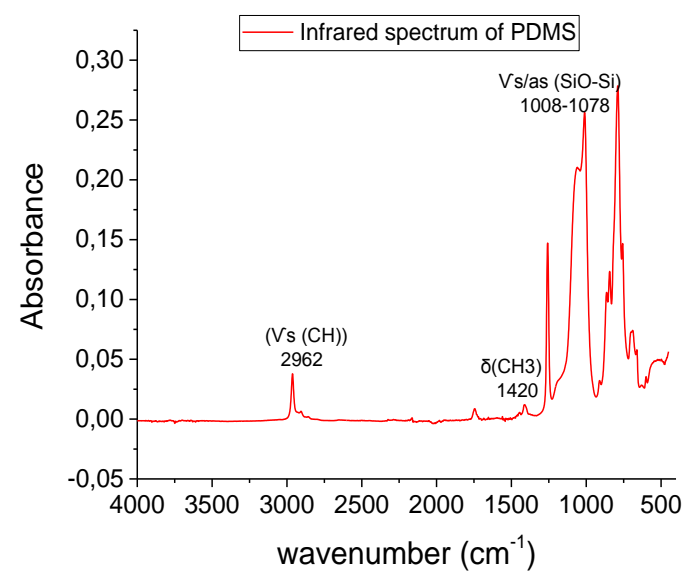

Figure 2 : IR spectra of PDMS (blank sample)

The first measurements for THC were conducted using a mix of gasoil and mineral oil and, $\mathrm{nC} 12$ and $\mathrm{nC} 30$ at a concentration of $500 \mathrm{mg} \cdot \mathrm{kg}^{-1}$ directly deposited in an empty vial. After the transfer to the sampler, the PDMS film was analyzed by ATR-FTIR (Figure 3). Thanks to the interactive subtraction of the spectrum of blank samples (PDMS only) from the sample spectrum (after exposition to THC), the infrared spectrum of hydrocarbons was obtained without PDMS interference.

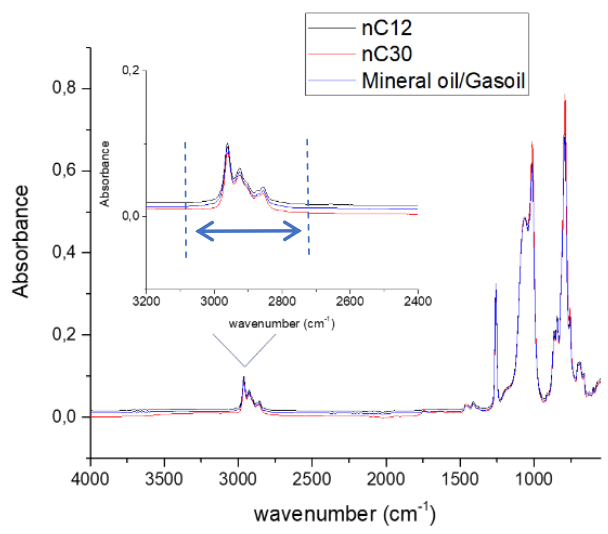

Figure 3 : Overlayed spectroscopic patterns of different hydrocarbons found in a thin layer of PDMS

IR spectra of hydrocarbon derivatives originate mainly from combinations or overtones of $\mathrm{C}$ - $\mathrm{H}$ stretching modes of saturated $\mathrm{CH}_{2}$ and terminal $-\mathrm{CH}_{3}$ or aromatic $\mathrm{C}-\mathrm{H}$ functional groups. In the $3000 \mathrm{~cm}^{-1}$ region, hydrocarbons have characteristic peaks at 2954,2872 , and $2926 \mathrm{~cm}^{-1}$ related to the stretching vibrations of methyl and methylene groups of hydrocarbons ${ }^{35}$.

In terms of the quantitative analysis of THC in soils, these are the most relevant responses. As for previous methods using now banned IR-transparent solvents $\left(\mathrm{CCl}_{4}\right.$, freon-113), the integration of absorption bands in the region 2850 and $2960 \mathrm{~cm}^{-1}$ has been widely used to quantify $\mathrm{THC}^{36}$. 
Quantification: In this study, standard addition (3 levels) was used instead of external calibration to avoid the matrix effects that resulted in relative systematic errors in previous studies ${ }^{37}$. With this method, the concentration of analyte in the unknown sample was then estimated by extrapolating the standard addition line to the zero response.

Practically the sample was spiked with a known quantity (400 and $2000 \mathrm{mg} \cdot \mathrm{kg}^{-1}$ ) of the standard solution (mix of mineral oil/gasoil). The volumes of THC standard added are present in (Table 1 SI). The different spiked samples were analysed and the results obtained by extrapolating the matrix-matched calibration lines allowed to find the initial concentration in spiked soil.

The accuracy of the method in the determination of THC concentrations from spiked soil was evaluated by the recovery values. The acceptance limits for THC recovery were based on the EPA 8000 guide which establishes the recovery interval from $70 \%$ to $130 \%{ }^{38}$. The RSD (\%) values were calculated from experimental repeatability.

The experimental accuracy is lower than $10 \%$ (average accuracy 6\%), so, the results were in good match with the expected concentration. Then, the procedure provided satisfactory recoveries between $90-110 \%$ with relative standard deviation values lower than $15 \%$.

However, only one recovery did not fall within the established limit (green clay at the concentration of 400 and $2000 \mathrm{mg} \cdot \mathrm{kg}^{-1}$ ). This soil was a pure montmorillonite clay, the extraction of THC was not efficient because the THC were probably trapped inside octahedral sheets in the clay ${ }^{39,40}$. Another factor that could affect the extraction efficiency is the clay's surface area, resulting in greater adsorption of the $\mathrm{THC}^{41}$. Schwab et al 1999 observed the same result, i.e. extraction efficiency of polyaromatic hydrocarbons $(\mathrm{PAH})$ for all solvents declining with increasing clay content in soil $^{42}$. Therefore, the TLSE- ATR -FTIR method appears to be accurate for the measurement of THC in all soils types except clay soil.

\section{Influence of soil parameters on extraction efficiency}

The Figure 4 shows the effects of soil characteristics and their interactions on the extraction of THC by TLSE-ATRFTIR. The significative limits are calculated by carrying out experiment 3 in triplicate which results in an RSD of $2.13 \%$. This is an indication that the method is repeatable.

According to Figure 4 the factors influencing the experimental response (integrated areas of $3000-2800 \mathrm{~cm}^{-1}$ aliphatic bonds) are total organic compounds (TOC), concentration of THC (Con. P.) and the nature of the soil (sandy or clay). They show a positive effect, which implies that the experimental response increases when these factors vary from level 1 to level 2. These are coherent since, on the one hand, soils with high organic carbon content allow significant adsorption of hydrocarbons, and on the other hand, for soils with low level of organic carbon such as Fontainebleau sand the adsorption of THC is very low so losses by volatilization of some hydrocarbons may take place.

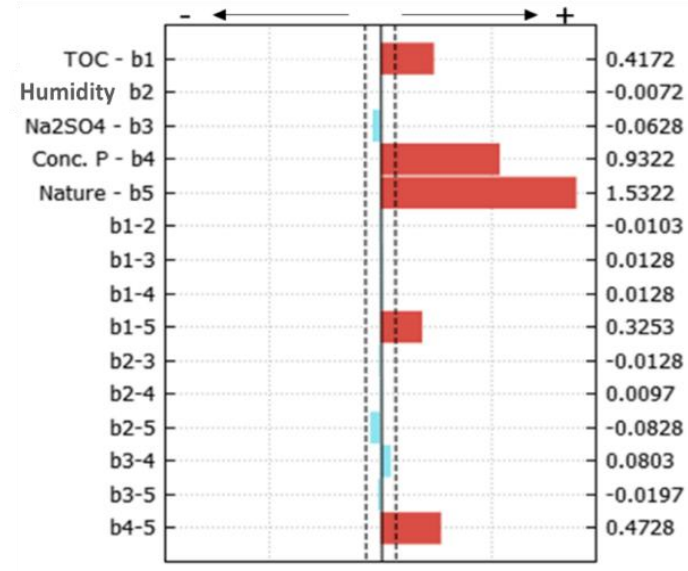

Figure 4 : Graphical study of the effects of factors influencing the extraction of THCs in soils

$\mathrm{b} 1, \mathrm{~b} 2, \mathrm{~b} 3, \mathrm{~b} 4$ and $\mathrm{b} 5$ the effects of factors; $\mathrm{b} 1-5, \mathrm{~b} 2-5, \mathrm{~b} 3-4, \mathrm{~b} 3-5$ et b4-5 the interaction effect between the factors and verticals dash line represents signification limits

Moreover, concerning THC concentration, it is completely coherent to have the response of the sampler, which increases with the concentration, since we are working in the linear domain of the method. The influence of soil's nature on the responses is also coherent and confirms the results previously discussed on analyzes of spiked soils.

Nevertheless, we find that the response is more important when sandy soil is extracted compared to clay soil. Last, humidity did not influence significantly the extraction method.

Figure 5 shows two significant interaction effects between TOC and the soil's nature and between the soil's nature and the THC concentration. The TOC does not have a significant influence on the THC extraction obtained for clay soils, and therefore on the quantities extracted by the film (Figure 5-A). 
Thus, the efficiency of the extraction is controlled by the nature of soil rather than the level of organic carbon on clay soil. However, for the sandy soil the response (area of the peaks) is multiplied by 1.5 when the organic carbon rate increases.

As shown in (Figure 5-B), for both of clay and sandy soils, the response is roughly multiplied by 2 when the concentration increases from 400 to $3000 \mathrm{mg} \cdot \mathrm{kg}^{-1}$. Even though the response increased in the case of clay soil, it remains smaller than that of sandy soils.

Thus, the recovery of sandy soil is significantly higher. These findings are in agreement with preliminary results obtained on spiked soils which show the difficulty for extracting THC from clay soils.
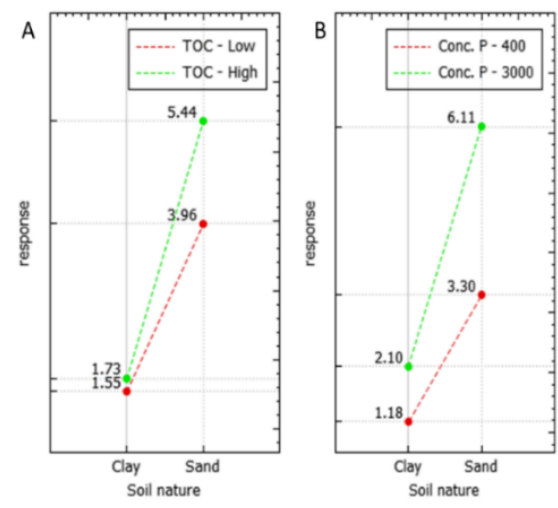

Figure 5 : Interaction factors diagram: A : TOC and the nature of soil and B :concentration of pollutant and nature of soil

\section{TLSE-ATR-FTIR Method validation}

To ensure accurate measurements of samples, the method validation, adapted from NF T90-210 was based on linearity, accuracy, precision and LOQ.

Linearity: The linearity of the proposed TLSE-ATR-FTIR method was evaluated according to the calibration, by analyzing a standard mixture of the studied substances at six different concentrations from 100 to $1000 \mathrm{mg} \cdot \mathrm{kg}^{-1}$. For each concentration, three replicates were carried out over different days. The calibration curves were constructed from the response versus the concentration of the standards. Regression analysis shows good linearity as indicated from the correlation coefficient values $\mathrm{R}^{2}$ and $\mathrm{R}^{2}$ adj above 0.99 for the both.

Accuracy: The accuracy of the TLSE-ATR-FTIR method was evaluated by the recovery values obtained after the extraction process and the concentrations have been determined using the standard addition method. Three soil samples were spiked at three concentration levels $\left(300,750\right.$ and $\left.1000 \mathrm{mg} \cdot \mathrm{kg}^{-1}\right)$ using standard solution mix of mineral oil/gasoil (described above). The results are presented in Table 3, which compare spiked samples and measured concentrations.

Table 3 : Accuracy results of [THC] spiked at 300, 750 and 1000 mg.kg ${ }^{-1}$ Accu: accuracy; Reco: recovery $(n=2)$

\begin{tabular}{|c|c|c|c|c|}
\hline Soil & $\begin{array}{c}\text { [THC] Spiked } \\
\left(\mathrm{mg}^{\left.-\mathrm{kg}^{-1}\right)}\right.\end{array}$ & $\begin{array}{l}{[\mathrm{THC}]_{\text {mean }}} \\
\left(\mathrm{mg} \cdot \mathrm{kg}^{-1}\right)\end{array}$ & $\begin{array}{c}\text { Accu } \\
(\%)\end{array}$ & $\begin{array}{c}\text { Reco } \\
\%\end{array}$ \\
\hline \multirow{3}{*}{ है } & 300 & 314 & 11 & 105 \\
\hline & 750 & 719 & 7 & 96 \\
\hline & 1000 & 982 & 7 & 98 \\
\hline \multirow{3}{*}{ 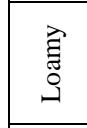 } & 300 & 294 & 1 & 98 \\
\hline & 750 & 729 & 6 & 97 \\
\hline & 1000 & 1069 & 1 & 107 \\
\hline \multirow{3}{*}{ 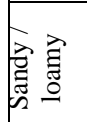 } & 300 & 315 & 3 & 105 \\
\hline & 750 & 760 & 5 & 101 \\
\hline & 1000 & 1089 & 14 & 109 \\
\hline
\end{tabular}

Since the accuracy is lower than $10 \%$, we can conclude that the results were in good agreement with the expected concentration. Thus, the results of THC quantitation measured with the TLSE-ATR-FTIR method are reliable. However, table 3 shows that for different soil types (sandy and loamy) we have recoveries around 100\%, but clay soil for which we have lower recoveries was not mentioned in this table. So, the method presents good recoveries for different types of soil except clay soils.

Precision: The precision of the TLSE-ATR-FTIR methods were evaluated by the following parameters: repeatability and intermediate precision by the relative standard deviation values obtained from peak area (RSD). The repeatability was determined by the analysis of 6 replicates at the lower, middle and upper points $\left(300,750\right.$ and $1000 \mathrm{mg}^{\mathrm{kg}} \mathrm{kg}^{-1}$ ) 
conducted the same day. The spiked soil was prepared following the method described above. Reproducibility (intermediate precision) was obtained by analyzing 6 replicates of the three concentrations, on different days.

Table 4 : Analytical parameters for the validation of precision of TLSE-ATR-FTIR analysis method $(\mathbf{n}=6)$ *: repeatability; **: reproducibility.

\begin{tabular}{|c|c|c|c|}
\hline Soil & $\begin{array}{c}{[\mathbf{T H C}]} \\
\left(\mathbf{m g . k g} \mathbf{- 1}^{-1}\right)\end{array}$ & $\begin{array}{c}\text { RSD } * \\
(\mathbf{\%})\end{array}$ & $\begin{array}{c}\text { RSD ** } \\
(\mathbf{\%})\end{array}$ \\
\hline \multirow{3}{*}{ Sandy/Loamy } & 300 & 6 & 7 \\
\cline { 2 - 4 } & 750 & 8 & 11 \\
\cline { 2 - 4 } & 1000 & 9 & 12 \\
\hline
\end{tabular}

Regarding the precision, all concentration levels presented low values of RSD. The analysis of 6 replicates at 300,750 and $1000 \mathrm{mg} \cdot \mathrm{kg}^{-1}$ resulted in repeatability of 6,8 and $9 \%$ respectively. The intermediate precision showed RSD value varying between 7 and $12 \%$. So $\%$ RSD values are lower than $15 \%$ both for repeatability and intermediate precision proving the good precision of the method.

LOQ: With an AQL of $20 \%$, presupposed LOQ have been validated for the spiked soil at $300 \mathrm{mg}^{-\mathrm{kg}^{-1}}$ in six times in duplicate. The determination of the LOQ is established by standard addition method and is performed in the conditions of intermediate precision. Furthermore \% RSD values are lower than $15 \%$ for all LOQ measured (Table 2 SI). Although with this method we can analyse lower concentrations of hydrocarbons in soil (100 mg.kg-1) by using thinner films and more quantity of soil

\section{TLSE-ATR-FTIR implementation to field contaminated soils}

After the validation of the TLSE-ATR-FTIR, 20 different soils, sampled from different regions in France were analyzed. These real soil samples had relatively distinct composition and physicochemical properties (Table 3 SI). After analysis, the results were compared to those obtained by accredited laboratories COFRAC (EUROFINS) with conventional analyzes carried out in the same time and in accordance with regulatory standards). The results are shown in Table 3 SI. As shown by Figure 6, the THC concentration of the various contaminated soils determined by TLSEATR-FTIR are in very good match with those supplied by the accredited laboratory. Last, TLSE technique always led to significantly lower standard deviations with low detection and quantification limits that meets regulatory requirements $\left(500 \mathrm{mg} \cdot \mathrm{kg}^{-1}\right)$.

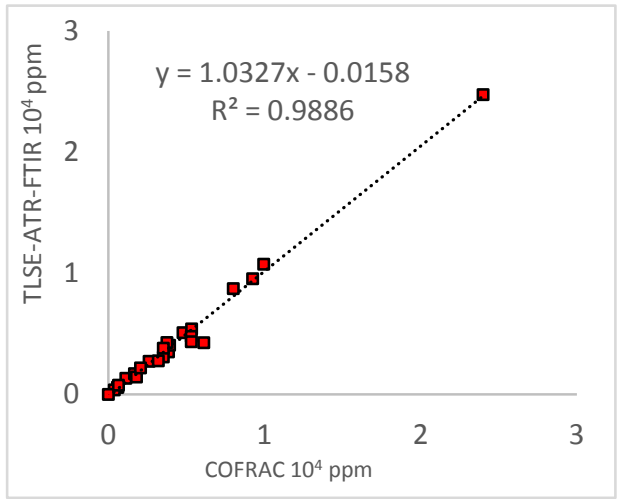

Figure 6 : Correlation between COFRAC concentration values and TLSE-ATR-FTIR THC values for 20 real contaminated soils.

In addition, the TLSE-ATR-FTIR method was applied directly on site on several campaigns in order to confirm its feasibility and to give direct results for engineering and design departments. For example, we used it during a field campaign where we analyzed hydrocarbons from soil as a part of a pollution control project carried out by Golder, company. The results obtained on site during these campaigns were promising and will be the subject of another publication (Figure SI 3). The Figure SI 3 shows some results obtained from the analysis of hydrocarbons directly on site.

\section{CONCLUSION}

This study constitutes the first application of a polymeric sampler for the determination of THC in soil. Indeed, this study resulted in the development and validation of a new extraction method by thermodesorption without solvent of 
THC from contaminated soil using a polymer sampler coupled with an analysis by ATR-FTIR. This innovative method is cheap, rapid, and the implementation is rather simple both in the lab and in situ. The TLSE-ATR-FTIR method has limitations of detection and quantification of $100 \mathrm{mg} \cdot \mathrm{kg}^{-1}$ and $300 \mathrm{mg} \cdot \mathrm{kg}^{-1}$, respectively. Recovery experiments with soil spiked with different physicochemical properties using the TLSE-ATR-FTIR procedure provided satisfactory recoveries between $90-110 \%$ and with relative standard deviation values lower than $15 \%$. Also, the TLSE-ATR-FTIR method for determination of THC were accurate. However, due to the limited desorption, the use of the TLSE-ATRFTIR is not recommended for clay soils contaminated with THC.

This study is the first step in developing an alternative technique for determining the presence of THC in soils. This alternative technique is fast, low-cost, solvent free and exhibit a good repeatability. The successful application of the TLSE-ATR-FTIR to contaminated soil is promising and suggests further work to confirm the feasibility of it use in "real world" on-site conditions for long term monitoring or risk studies operated by engineering and design departments.

\section{ASSOCIATED CONTENT}

\section{Supporting Information}

The Supporting Information is available free of charge on the ACS Publications website. Figure SI 1 show the evolution of THC concentrations in silicone film PDMS as a function of the exposure duration and Figure SI 2, the thickness of the PDMS film as a function of spin speed. Table SI 1 show the accuracy, recovery and RSD results of measured concentrations of THC spiked at 400 and 2000mg.kg ${ }^{-1}(\mathrm{n}=3)(\mathrm{PDF})$ and Table SI 2 show the validation of the LOQ values for studied compounds in TLSE-ATR-FTIR method $(\mathrm{n}=5)$ (PDF). The accuracy between HCT's concentrations in 20 real soils obtained by TLSEATR-FTIR with those provided by the accredited laboratory is shown in Table SI 3. Finally, the Figure SI 3 show the comparison between COFRAC concentration values and TLSE-ATR-FTIR THC values for real contaminated soils analyses on site.

\section{ACKNOWLEDGMENT}

The authors would like to thank the MATRICE project for funding this research, Prof. Catherine Keller for soil samples, and Vegatec for the heating block.

\section{AUTHOR INFORMATION}

\section{Corresponding Author}

* Maria Sébastien - Aix-Marseille University - Institut de Chimie Radicalaire - Email : sebastien.maria@univ-amu.fr Phone : $+33(0) 491288192$

\section{REFERENCES}

(1) Valentín, L.; Nousiainen, A.; Mikkonen, A. Introduction to Organic Contaminants in Soil: Concepts and Risks. The Handbook of Environmental Chemistry; Springer: Berlin, Heidelberg, 2013; pp 1-29. https://doi.org/10.1007/698_2012_208.

(2) Park, I.-S.; Park, J.-W. Determination of a Risk Management Primer at Petroleum-Contaminated Sites: Developing New Human Health Risk Assessment Strategy. J. Hazard. Mater. 2011, 185 (2), 1374-1380. https://doi.org/10.1016/j.jhazmat.2010.10.058.

(3) Varjani, S. J. Microbial Degradation of Petroleum Hydrocarbons. Bioresour. Technol. 2017, $223,277-286$. https://doi.org/10.1016/j.biortech.2016.10.037.

(4) Ossai, I. C.; Ahmed, A.; Hassan, A.; Hamid, F. S. Remediation of Soil and Water Contaminated with Petroleum Hydrocarbon: A Review. Environ. Technol. Innov. 2019. https://doi.org/10.1016/j.eti.2019.100526.

(5) Arrêté Du 12 Décembre 2014 Relatif Aux Conditions d'admission Des Déchets Inertes Dans Les Installation.

(6) Paíga, P.; Mendes, L.; Albergaria, J. T.; Delerue-Matos, C. M. Determination of Total Petroleum Hydrocarbons in Soil from Different Locations Using Infrared Spectrophotometry and Gas Chromatography. Chem. Pap. 2012, 66 (8), 711-721. https://doi.org/10.2478/s11696012-0193-8.

(7) Sadler, R.; Connell, D. Analytical Methods for the Determination of Total Petroleum Hydrocarbons in Soil. $2003,20$.

(8) Miclean, M.; Levei, E.-A.; Gog, A.; Ferenczi, L.; Majdik, C.; Puia, C.; Roman, C. Determination of Total Petroleum Hydrocarbons in Contaminated Soil by FTIR and GC-FID Methods. Stud. Univ. Babes-Bolyai Chem. 2010, 55, 83-91.

(9) Lambert, P.; Fingas, M.; Goldthorp, M. An Evaluation of Field Total Petroleum Hydrocarbon (TPH) Systems. J. Hazard. Mater. 2001, 83 (1), 65-81. https://doi.org/10.1016/S0304-3894(00)00328-9.

(10) Becker, R.; Koch, M.; Wachholz, S.; Win, T. Quantification of Total Petrol Hydrocarbons (TPH) in Soil by IR-Spectrometry and Gas Chromatography - Conclusions from Three Proficiency Testing Rounds. Accreditation Qual. Assur. 2002, 7 (7), $286-289$. https://doi.org/10.1007/s00769-002-0476-9.

(11) Horta, A.; Malone, B.; Stockmann, U.; Minasny, B.; Bishop, T. F. A.; McBratney, A. B.; Pallasser, R.; Pozza, L. Potential of Integrated Field Spectroscopy and Spatial Analysis for Enhanced Assessment of Soil Contamination: A Prospective Review. Geoderma 2015, 241-242, 180-209. https://doi.org/10.1016/j.geoderma.2014.11.024.

(12) Wright, K. A. EVALUATION OF A NEW FIELD TEST KIT FOR DETERMINING TOTAL PETROLEUM HYDROCARBON CONCENTRATIONS IN SOIL AT A SITE CONTAMINATED BY DIESEL FUEL. 9.

(13) Webster, G. T.; Soriano-Disla, J. M.; Kirk, J.; Janik, L. J.; Forrester, S. T.; McLaughlin, M. J.; Stewart, R. J. Rapid Prediction of Total Petroleum Hydrocarbons in Soil Using a Hand-Held Mid-Infrared Field Instrument. Talanta 2016, 160, $410-416$. https://doi.org/10.1016/j.talanta.2016.07.044.

(14) Wang, L.; Cheng, Y.; Lamb, D.; Naidu, R. The Application of Rapid Handheld FTIR Petroleum Hydrocarbon-Contaminant Measurement with Transport Models for Site Assessment: A Case Study. Geoderma 2020, 361, 114017. https://doi.org/10.1016/j.geoderma.2019.114017.

(15) Ng, W.; Malone, B. P.; Minasny, B. Rapid Assessment of Petroleum-Contaminated Soils with Infrared Spectroscopy. Geoderma 2017, 289, 150-160. https://doi.org/10.1016/j.geoderma.2016.11.030. 
(16) Hazel, G.; Bucholtz, F.; Aggarwal, I. D.; Nau, G.; Ewing, K. J. Multivariate Analysis of Mid-IR FT-IR Spectra of HydrocarbonContaminated Wet Soils. Appl. Spectrosc. 1997, 51 (7), 984-989.

(17) Malley, D. F.; Hunter, K. N.; Webster, G. R. B. Analysis of Diesel Fuel Contamination in Soils by Near-Infrared Reflectance Spectrometry and Solid Phase Microextraction-Gas Chromatography. J. Soil Contam. 1999, 8 (4), $481-489$. https://doi.org/10.1080/10588339991339423.

(18) Schwartz, G.; Ben-Dor, E; Eshel, G. Quantitative Analysis of Total Petroleum Hydrocarbons in Soils: Comparison between Reflectance Spectroscopy and Solvent Extraction by 3 Certified Laboratories. Appl. Environ. Soil Sci. 2012, 2012 , 1-11. https://doi.org/10.1155/2012/751956.

(19) Chakraborty, S.; Weindorf, D. C.; Zhu, Y.; Li, B.; Morgan, C. L. S.; Ge, Y.; Galbraith, J. Assessing Spatial Variability of Soil Petroleum Contamination Using Visible Near-Infrared Diffuse Reflectance Spectroscopy. J. Environ. Monit. 2012, 14 (11), $2886-2892$. https://doi.org/10.1039/C2EM30330B.

(20) Tang, Liang.; Kebarle, Paul. Dependence of Ion Intensity in Electrospray Mass Spectrometry on the Concentration of the Analytes in the Electrosprayed Solution. Anal. Chem. 1993, 65 (24), 3654-3668. https://doi.org/10.1021/ac00072a020.

(21) Pejcic, B.; Myers, M.; Ross, A.; Pejcic, B.; Myers, M.; Ross, A. Mid-Infrared Sensing of Organic Pollutants in Aqueous Environments. Sensors 2009, 9 (8), 6232-6253. https://doi.org/10.3390/s90806232.

(22) Stach, R.; Pejcic, B.; Crooke, E.; Myers, M.; Mizaikoff, B. Mid-Infrared Spectroscopic Method for the Identification and Quantification of Dissolved Oil Components in Marine Environments. Anal. Chem. 2015, 87 (24), $12306-12312$. https://doi.org/10.1021/acs.analchem.5b03624.

(23) Alimzhanova, M. B.; Abilev, M. B.; Kuandykova, M. M.; Kenessov, B. N.; Kamysbayev, D. K. Rapid Screening Method for the Total Petroleum Hydrocarbons in Water Samples by Solid-Phase Microextraction and GC-MS. Eurasian Chem.-Technol. J. 2012, 14 (2), 177. https://doi.org/10.18321/ectj112.

(24) Smith, K. E. C.; Wick, L. Y. Solid Phase Microextraction (SPME) for Determining the Freely Dissolved Concentrations of Oil Hydrocarbons. In Handbook of Hydrocarbon and Lipid Microbiology; Timmis, K. N., Ed.; Springer: Berlin, Heidelberg, 2010; pp 35833591. https://doi.org/10.1007/978-3-540-77587-4_281.

(25) Cam, D.; Gagni, S. Determination of Petroleum Hydrocarbons in Contaminated Soils Using Solid-Phase Microextraction with Gas Chromatography-Mass Spectrometry. J. Chromatogr. Sci. 2001, 39 (11), 481-486. https://doi.org/10.1093/chromsci/39.11.481.

(26) Jager, M. J.; McClintic, D. P.; Tilotta, D. C. Measurement of Petroleum Fuel Contamination in Water by Solid-Phase Microextraction with Direct Raman Spectroscopic Detection. Appl. Spectrosc. 2000, 54 (11), 1617-1623

(27) Eriksson, M.; Swartling, A.; Dalhammar, G.; Fäldt, J.; Borg-Karlson, A.-K. Biological Degradation of Diesel Fuel in Water and Soil Monitored with Solid-Phase Micro-Extraction and GC-MS. Appl. Microbiol. Biotechnol. 1998, 50 (1), $129-134$. https://doi.org/10.1007/s002530051267.

(28) Merkel, T. C.; Bondar, V. I.; Nagai, K.; Freeman, B. D.; Pinnau, I. Gas Sorption, Diffusion, and Permeation in Poly(Dimethylsiloxane). J. Polym. Sci. Part B Polym. Phys. 2000, 38 (3), 415-434. https://doi.org/10.1002/(SICI)10990488(20000201)38:3<415::AID-POLB8>3.0.CO;2-Z

(29) Seethapathy, S.; Górecki, T. Applications of Polydimethylsiloxane in Analytical Chemistry: A Review. Anal. Chim. Acta 2012, 750, 48-62. https://doi.org/10.1016/j.aca.2012.05.004.

(30) X31-410 - Septembre 1994 https://www.boutique.afnor.org/norme/x31-410/qualite-du-sol-dosage-des-huiles-minerales-methode-parspectrometrie-a-l-infrarouge-et-methode-par-chromatographie-en-phase-/article/863200/fa038523 (accessed Mar 2, 2020).

(31) Bocard, C. Marées noires et sols pollués par des hydrocarbures: enjeux environnementaux et traitement des pollutions; Editions TECHNIP, 2006

(32) Tosheva, L.; Doyle, A. M. Chapter 19 - Strategies Towards the Assembly of Preformed Zeolite Crystals into Supported Layers. In Ordered Porous Solids; Valtchev, V., Mintova, S., Tsapatsis, M., Eds.; Elsevier: Amsterdam, 2009 ; pp 501-519. https://doi.org/10.1016/B978-0-444-53189-6.00019-6.

(33) Aguilera-Herrador, E.; Lucena, R.; Cárdenas, S.; Valcárcel, M. Continuous Flow Configuration for Total Hydrocarbons Index Determination in Soils by Evaporative Light Scattering Detection. J. Chromatogr. A 2007, 1141 (2), $302-307$. https://doi.org/10.1016/j.chroma.2006.12.021

(34) Lima, É. C.; Adebayo, M. A.; Machado, F. M. Kinetic and Equilibrium Models of Adsorption. In Carbon Nanomaterials as Adsorbents for Environmental and Biological Applications; Bergmann, C. P., Machado, F. M., Eds.; Springer International Publishing: Cham, 2015; pp 33-69. https://doi.org/10.1007/978-3-319-18875-1_3.

(35) Guryanova, A.; Ermakov, V.; Galyanin, V.; Artyushenko, V.; Sakharova, T.; Usenov, I.; Bykov, D.; Bogomolov, A. Quantitative Analysis of Total Hydrocarbons and Water in Oil-Contaminated Soils with Attenuated Total Reflection Infrared Spectroscopy. J. Chemom. 2017, 31 (8), e2826. https://doi.org/10.1002/cem.2826

(36) Aske, N.; Kallevik, H.; Sjöblom, J. Determination of Saturate, Aromatic, Resin, and Asphaltenic (SARA) Components in Crude Oils by Means of Infrared and Near-Infrared Spectroscopy. Energy Fuels 2001, 15 (5), 1304-1312. https://doi.org/10.1021/ef010088h.

(37) Harris, D. C. Quantitative Chemical Analysis; W. H. Freeman, 2010.

(38) METHOD 8000C - DETERMINATIVE CHROMATOGRAPHIC SEPARATIONS. 2003, 66

(39) Awad, A. M.; Shaikh, S. M. R.; Jalab, R.; Gulied, M. H.; Nasser, M. S.; Benamor, A.; Adham, S. Adsorption of Organic Pollutants by Natural and Modified Clays: A Comprehensive Review. Sep. Purif. Technol. 2019, 228, 115719. https://doi.org/10.1016/j.seppur.2019.115719.

(40) Li, Y.; Gupta, G. Adsorption/Desorption of Hydrocarbons on Clay Minerals. Chemosphere 1994, 28 (3), 627-638. https://doi.org/10.1016/0045-6535(94)90304-2.

(41) Analysis of Petroleum Hydrocarbons in Environmental Media; Weisman, W., Total Petroleum Hydrocarbon Criteria Working Group, Eds.; Total Petroleum Hydrocarbon Criteria Working Group series; Amherst Scientific Publishers: Amherst, Mass, 1998.

(42) Schwab, A. P.; Su, J.; Wetzel, S.; Pekarek, S.; Banks, M. K. Extraction of Petroleum Hydrocarbons from Soil by Mechanical Shaking.

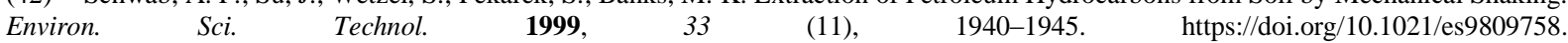

\section{For Table of}

